
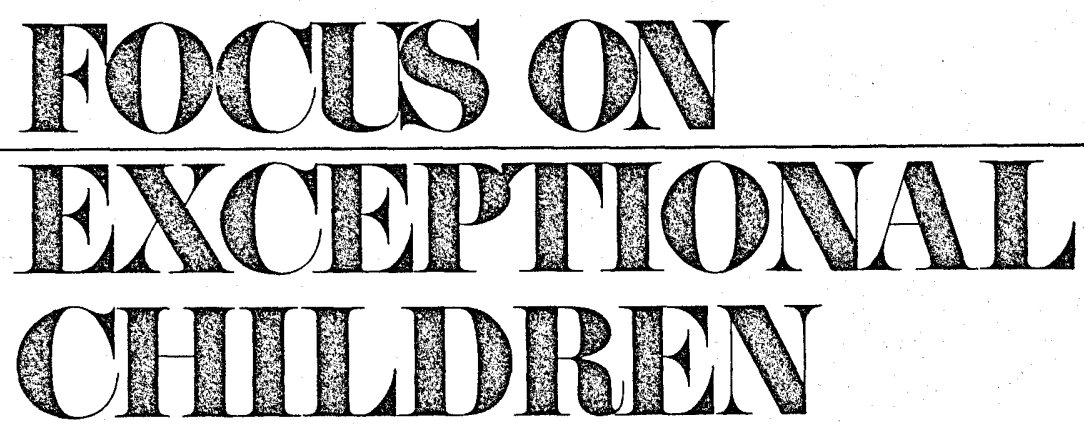

\title{
Listening Skills: \\ Teaching Learning Disabled Students to be Better Listeners
}

\section{Suzanne Robinson and Deborah Deutsch Smith}

A person's ability to listen with understanding is essential to good communication. Its importance in all life settings - school, job, and social interaction - cannot be denied. In the 1980s the primary forms of information dissemination require one to listen; these include TV, radio, telephone, teachers, supervisors, and friends. Research verifies that people spend the majority of each day engaged in communication, and most of that time is in listening. Rankin's (1930) thorough and often cited study of verbal communication found that $70 \%$ of an average adult's waking time was spent in either reading, writing, listening, or speaking. Further analysis of the data showed that subjects spent $30 \%$ of their waking hours each day speaking, $16 \%$ reading, $9 \%$ writing, and $45 \%$ listening. Wilt (1949) found that children in elementary school spent $54 \%$ of their time listening. As children progress from elementary to middle to high school, listening is required for increasingly more of the school day.

Yet, the teaching of listening is often ignored or, at best, inconsistently addressed as an integral part of any school curriculum. Many teachers assume that listening skills develop automatically with other communication skills. In these areas that "develop automatically," however, the exceptional child often has great difficulty. In fact, the little research that has been conducted concerning exceptional students and listening has revealed that the learning disabled do not exhibit "normal" developmental levels of listening comprehension (Bauer, 1977; Kotsonis \& Patterson, 1980). In the studies, learning disabled students as compared with "normal" peers remembered less and did not monitor whether they understood what they heard.

This difficulty with listening is observed so frequently (if not validated empirically) that the Federal Register's definition of learning disabilities cites disorders in listening as an identifying characteristic of the learning disabled child. Despite this, teachers often expect their learning disabled students to supplement or compensate for poor reading and writing skills with listening via tapes, films, filmstrips, or lecture. Therefore, teachers might be doing their exceptional students a disservice if they do not instruct them in how to be better listeners.

Suzanne Robinson is a graduate assistant and doctoral student in special education at the University of New Mexico, and was a teacher of learning disabled children in Longmont, Colorado. Deborah Smith is Associate Professor of Special Education and Assistant Department Chair of the Special Education Department of the University of New Mexico. 
Substantial research documents that better listening can be taught. Devine (1978) reviewed this body of literature and found that direct instruction can improve listening skills. In another study Cosgrove and Patterson (1978) found that not only could listening be taught, but when given a task approach strategy (or plan on how to listen effectively) to use with one set of stimuli, the training generalized to different stimuli. In this case the task approach strategy consisted of instructions to stop the speakers and ask questions to help clarify what was heard. Often, a gain in other communication skills, such as speaking, was noted as well (Sonnenschein \& Whitehurst, 1980).

Since listening skills can be taught and learning disabled children have difficulty with listening, this area of instruction should be included in curricula for these children. We are suggesting a viable approach to teaching better listening skills, in this article. We are proposing a model to define and sequence the behaviors contained in listening and observational guidelines to pinpoint where instruction should begin. These are followed by exploration of instruction using approach or cognitive strategies as a way to facilitate better listening. A review of materials currently available concludes the article.

\section{DEFINITIONS FOR LISTENING}

There is no widely accepted definition of listening. Agreement exists, however, on a few points. First,

FOCUS ON EXCEPTIONAL CHILDREN (ISSN 0015-5IIX) (USPS 203-360) is published monthly except June, July, and August as a service to teachers, special educators, curriculum specialists, administrators, and those concerned with the special education of exceptional children. This journal is abstracted and indexed in Exceptional Child Education Resources, and is also available in microform from Xerox University Microfilms, Ann Arbor, Michigan. Subscription rates, \$13.50 per year. Copyright 1981, Love Publishing Company. All rights reserved. Reproduction in whole or part without written permission is prohibited. Printed in the United States of America. Second class postage is paid at Denver, Colorado. POSTMASTER: Send address changes to:

Love Publishing Company

Executive and Editorial Office

1777 South Bellaire Street

Denver, Colorado 80222

Telephone (303) 757-2579

\section{EDITORIAL BOARD}

Edward L. Meyen University of Kansas

Richard J. Whelan

University of Kansas Medical Center

Carolyn Acheson

Senior Editor

Stanley F. Love Publisher listening is more than hearing; it is more than attending to sounds. Barker (1971), after reviewing numerous definitions, defined listening as "the selective process of attending to, hearing, understanding and remembering aural symbols" (p. 17). Alley and Deshler (1979) supplemented this definition by including attention to and comprehension of nonverbal messages along with verbal messages. The nonverbal component incorporates paralinguistic communication, or tone of voice, loudness, speed, and pauses that convey meaning by emphasis or lack of it; and visual communication, which includes the visual impression the speaker creates by dress and hair style. The third element of the nonverbal component is kinesic communication or body movement, which consists of posture, facial expressions, and use of body parts (e.g., pointing, hand waving).

Listening also is defined qualitatively. Barbara (1957) differentiated between active and passive listening by stating:

In the former, the individual listens with more or less his total
self - including his special senses, attitudes, beliefs, feelings
and intuitions. In the latter, the listener becomes mainly an
organ for the passive reception of sound, with little self-percep-
tion, personal involvement, gestalt discrimination, or alive
curiosity. (p. 12)

These three definitions combined describe the act of listening. More emphasis, however, should be placed on the interactional nature of listening, and any operational definition must consider the possible variations in each component.

\section{A MODEL TO DEFINE LISTENING}

Although the definitions describe the act of listening, they lack criteria that would enable the teacher to know when the listener has indeed "listened well." They do not help the teacher decide where to begin when instructing youngsters in listening skills, and they do not clearly delineate components that could be modified to improve listener performance.

Listening may indeed elude a simple behavioral definition. Yet, research has shown that identifying specific components of a task is the initial step to efficient instruction (Mager \& Beach, 1967; Smith, 1981). Direct observation and measurement of a student's performance are known to be effective, when paired with instruction, in knowingly causing child change (Smith, 1981). Because listening is a complex task, this is difficult to do. Nevertheless, a model is suggested here to facilitate discussion of possible teaching strategies to increase good listening (see Figure 1). 
Listening skills are divided into three major parts: input (or the message), listening, and output (or observable response). An awareness of all three is essential for appropriate instruction. Each part of the listening sequence has several components. A description of each follows.

\section{Input - the Message}

Input, or the message, consists of the words, sounds, and nonverbal message the "speaker" conveys to the "listener." The way in which these components interact has an effect on listening (Alley \& Deshler, 1979; Barker, 1971; Ironsmith \& Whitehurst, 1978; Sonnenschein \& Whitehurst, 1980). A short description of each characteristic of the message follows.

\section{Clarity/Articulation}

Clarity of articulation refers to the mechanics of creating sounds. If someone's speech is poorly articulated, or if there is a difference in dialect, the message is more difficult for the listener to perceive. If competing sounds or noises are present in the environment, this also interferes with the clarity of the message.

\section{Vocabulary Level}

The speaker's level or range of vocabulary influences the listener's ability to respond appropriately. If the vocabulary in the message is too difficult, the listener is not likely to understand the message.

\section{Complexity}

Complexity refers to the type of message the speaker wants to convey. The conceptual level expressed, though possibly framed in simple vocabulary, may be more sophisticated than the listener has encountered in past experience.

\section{Duration}

The length of the message can affect the listener. Too much material or repetitions of the same information can be confusing.

\section{Informative/Ambiguous}

Research has shown that children have difficulty detecting the difference between ambiguous and informative messages, although this ability improves at a consistent rate through the beginning of adolescence (Asher, 1976; Ironsmith \& Whitehurst, 1978). Therefore, quality of the message plays a part in the listener's ability to respond appropriately.

\section{Nonverbal Messages}

Much has been written about the messages people convey nonverbally (Gordon, 1970; Shelton, 1974). In addition to auditory clues, the listener must comprehend visual clues that signify certain emphases. For example, mood, emotional importance of the message to the speaker, or important points can be conveyed nonverbally.

Obviously, the message can become complex, and the possible variations are infinite. The listener must exhibit great flexibility in listening, to receive and then act upon many different messages.

\section{Listening - The Cognitive Process}

What is necessary for the listener to take a message and transform it into an appropriate response? At this point in the listening process, the exceptional child often has difficulty. Yet, little research has been done to examine the learning disabled child's listening behavior. Some possible components necessary for good listening behavior, however, have been identified.

\section{Prerequisite Skills}

Attention. First, there are some prerequisite skills to listening. One of these is attention. The listener must attend to the speaker.

Acoustic competence. The next prerequisite skill is acoustic competence. The listener must be able to hear correctly that which was said. A person's acoustic competence, or acuity, must be sufficient for accurate reception of the messages.

Language competence. The third prerequisite skill is language competence. One must be able to perceive and discriminate the various sounds and combinations of 
INPUT (the message)

Clarity/Articulation

Vocabulary level

Complexity

Duration

Informative/Ambiguous

Nonverbal communication

LISTENING (the cognitive process)

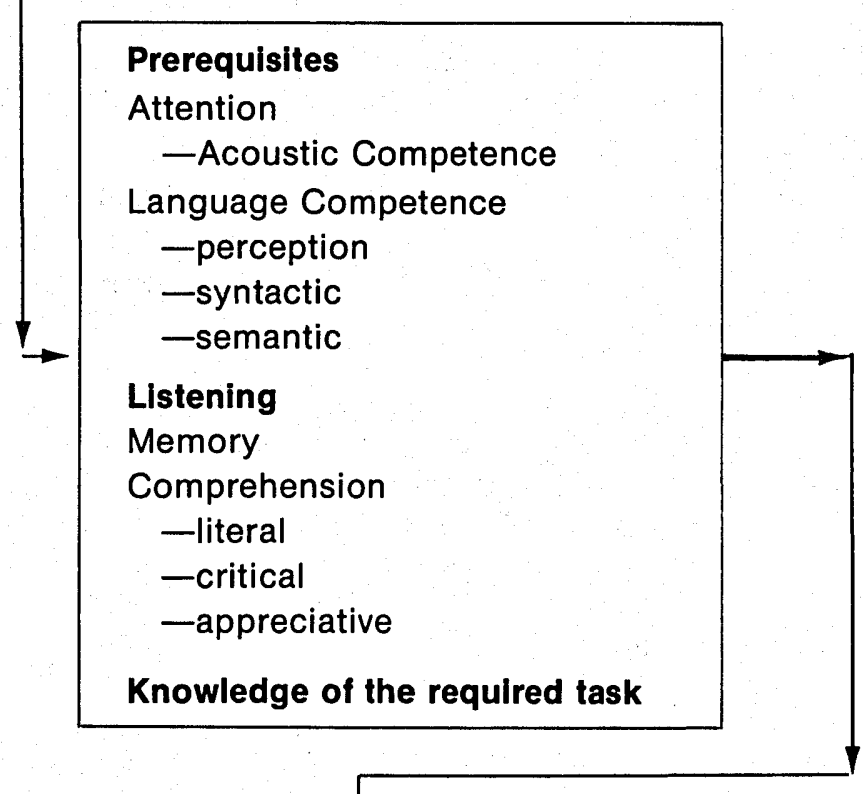

OUTPUT (the observable response)

Verbal Response

Physical (Motoric) Response

Written Response

Clarifying verbal response 
sounds used to create words. One must have the syntactic and semantic skills to allow understanding of what the speaking is saying. Within the child's repertoire must be the vocabulary to allow for decoding and understanding the message. The level of language competence, therefore, either facilitates or interferes with good listening.

\section{Listening}

Comprehension. What a person does to "understand" or "comprehend" is not clearly understood. One can tell, however, when comprehension occurs because of the response the listener gives. For example, a person may give a complex set of directions over the phone to meet a friend somewhere. That person does or does not arrive at the destination depending on whether the message was understood. Or a child, after hearing a story, might later restate it to someone else, indicating that the child "understood" what was heard.
Memory. Memory appears to be important and intrinsic to comprehension. If the information is not encoded or remembered, the cognitive processes to interpret the information cannot occur (Humphreys, Hall, \& Wilson, 1980). Comprehension activities, which incorporate memory, range from simple to complex. Alley and Deshler (1979), in their review of listening taxonomies, compiled a detailed sequence (please refer to Table 1) that can be used to further define the many levels of comprehension.

\section{Output - The Observable Response}

The third major component of the listening model is output, or the listener's response. This component is necessary for teachers to have verification that acceptable listening has taken place. Instructional success, therefore, must be measured by evaluating the listener's response. Three outputs or responses are possible: a

\section{Table 1}

\section{Listening Sequence to Define Comprehension}

1. Understanding words and concepts, and building a listening vocabulary

2. Understanding sentences and other linguistic elements of language

\section{Auditory memory}

4. Listening Comprehension (literal)

a. Understanding the relationship of details to main ideas

b. Following directions

c. Following the sequence of the message

d. Listening for details

e. Listening to a question with an intent to answer

f. Repeating what has been heard

From Teaching the Learning Disabled Adolescent: Strategies and Methods, by G. Alley and D. Deshler (Denver: Love Publishing Co., 1979), p. 282.
5. Critical Listening (evaluative/inference)

a. Recognizing absurdities

b. Recognizing propaganda

c. Correct me

d. Finishing stories

e. Distinguishing between fact and opinion

f. Detecting bias and prejudice

g. Distinguishing between emotive and report language

h. Evaluating speaker's argument

i. Drawing inferences and making judgments

j. Understanding sales pressure

k. Recognizing repetition of the same idea in different words

6. Appreciative Listening

a. Listening to visualize

b. Listening for rhythms of speech

c. Recognizing tone and mood

d. Appreciating speaker's style

e. Interpreting character from dialogue

f. Understanding effect on listeners of speaker's vocal quality

g. Understanding effect of audience on listener's reactions. 
motoric response (body movement), a verbal response, and a written response. A verbal response that clarifies the input and starts the sequence again is in fact a strategy to increase comprehension and is discussed in greater depth later.

\section{IMPLICATIONS FOR INSTRUCTION}

\section{Pinpointing Areas of Difficulty}

Direct observation and measurement of a child's performance represent an effective way to target the learner's entry level in any instructional situation. Difficulties in using this procedure to measure listening performance stem from the lack of consensus regarding the essential components of listening and difficulty in controlling the environment (or the message) sufficiently to measure listening adequacy consistently. Still, if one adopts a sequence of listening behaviors, observational data about various listening tasks and the child's listener characteristics can be collected.

The first step for efficient instruction is to identify the listening skills the learner possesses or lacks. The second step is to analyze the speaker's message or communication skills. Finally, one must be aware of the interaction and environmental climate in which the listener and speaker are involved.

\section{Attention}

Referring back to the listening model (see Figure 1), it is evident that learning disabled children often have difficulty in many or all of the skills involved in the cognitive process of listening. Research on attentional deficits in learning disabled students is substantial (Tarver \& Hallahan, 1974). The learning disabled child often has difficulty filtering out extraneous stimuli and attending selectively to the focal task. The absence of this prerequisite skill may inhibit good listening behavior; thus, attempts should be made to identify it at the learner's entry level.

\section{Language Competence}

Language competence is another prerequisite skill. The possible language problems a learning disabled child may have are well documented (Wiig \& Semel, 1980). If a child's semantic and syntactic language skills are not as sophisticated as those contained in the message, the child could have trouble responding properly.

\section{Memory}

In recent years learning disabled children have been characterized as "inactive learners" (Torgesen, 1977). Inactive learners do not approach tasks efficiently, and they are not aware of the responsibility in utilizing information to complete learning tasks independently. Active participation requires learners to be aware of their own cognitive processes, strengths and weaknesses, and demands of the task. Active learners use this awareness to apply cognitive strategies to ensure goal completion. Children who actively organize and structure the information they receive do better on memory tasks than children who do not.

From research on the development of memory, the concept of active participation in learning appears intrinsic to normal development. Researchers have demonstrated the importance of active rehearsal strategies in memory tasks (Flavell, 1971; Hagen, 1967; Keeny, Cannizzo \& Flavell, 1967). Others (Bauer, 1977; Hallahan \& Kneedler, 1979; Lloyd, 1980) have shown that the lack of such strategies (such as rehearsal or organization) in memorization attempts by both learning disabled and normal children results in poorer performance than was exhibited by those who used such memory strategies. Therefore, a child deficient in memorization strategies could experience difficulty in responding accurately after listening to a message.

\section{Comprehension}

If a child does not comprehend the information given, that child will have difficulty responding appropriately to the message. Research has shown that a child's monitoring comprehension (that is, the ability to evaluate one's level of understanding of incoming messages) progresses developmentally throughout the elementary years. Younger children do not discriminate as easily as do older children whether information given is adequate for understanding (Ironsmith \& Whitehurst, 1978; Markman, 1977).

Little research has compared the development of comprehension monitoring in normal children to that of learning disabled children. In one study, Kotsonis and Patterson (1980) found that learning disabled youngsters of varying ages consistently felt they had enough information to do the task when in fact they did not. 
Their skills in comprehension monitoring were significantly less than those of their normal peers. This lack in evaluation of message quality could cause difficulty in successfully completing a listening task.

\section{Knowledge of the Task Required}

Finally, the teacher must make sure the child can in fact do the requested task. For example, if the child is asked to respond to a message by writing, the child must know how to write. The child must also be able to write the words required in the response. Assessment by the teacher of the appropriateness of the performance mode is essential to planning an instructional sequence.

\section{INTERVENTION STRATEGIES}

\section{Modifying Speaker Input}

Listening skills can be taught in a variety of ways. An underlying structure or sequence is desirable to increase the flow of skill acquisition. Using the model suggested here, intervention strategies either modify and control the input, modify the listening behavior, or modify both at the same time. First, intervention can take place with the speaker (see Table 2). The message can be modified to increase attention, accommodate listener language competence, or facilitate the listener's memory and comprehension skills. This controlled message can be varied, depending on listener competence, at each level of the comprehension sequence (i.e., literal comprehension, critical listening, appreciative listening, and their respective subskills).

Controlling input to accommodate the learner's level of task proficiency is an instructional strategy often used in teaching exceptional children. To control the content of the message, the speaker must first be aware of factors influencing listener comprehension: clarity, vocabulary level, complexity of ideas presented, duration, informative quality, and nonverbal components. Specific modifications of the input, depending on listener characteristics, can then take place.

\section{Attention}

The speaker can facilitate listener attention in a variety of ways. Telling the child to listen or indicating that what will be said next is important can focus the child's attention on the task. Some researchers have found reinforcement or teacher attention to be an effective strategy to increase attending (Hallahan \& Kauffman, 1975; Kazdin, 1973). Controlling the environment by reducing extraneous noise or increasing proximity of the speaker to the listener are other useful techniques to promote attention. The speaker can also use a visual aid to focus the listener on important points.

\section{Language Competence}

The speaker must be aware of the listener's functional levels in areas of syntax and vocabulary. Input can then be simplified, shortened, or restated to facilitate task completion by the listener. When adequate listening performance is hampered by the student's lack of language proficiency, in-depth language development intervention could be necessary.

\section{Memory}

Enhancement of listener recall can be consistently.and systematically addressed if the speaker is knowledgeable of the organizational strategies used in memorization. Wiig and Semel (1980) have discussed in depth various elements that can be controlled in intervention. These variables are word frequency, associative strength, logical relationships, linguistic structure, length, serial position, intonation, and salience or immediate relevance.

Words commonly used in everyday speech are considered high frequency words. High frequency words tend to be recalled more eaily than low frequency words (Wiig \& Semel, 1980). Therefore, this variable should be controlled in planned interventions. Numerous resources that list high frequency words are available (Dolch, 1936; Thorndike \& Lorge, 1944).

Associative strength refers to the connection that can be made between important words in a message. Words that have a strong association, such as "knife, fork, spoon," are easier to recall by chunking together than is a series like "dog, car, apple." This logical grouping can be analyzed further. The type of association between important words is hierarchical in ease of recall. Words that can be grouped by semantic class membership (what: fruits - apples, oranges, peaches) are easier to remember than those grouped spatially (where: in the refrigerator - milk, catsup, meat) or by temporal relationships (when: at night - moon, dark, sleep) (Wiig \& Semel, 1980). 


\section{Table 2}

Strategies to Modify Input (The Message)

INPUT

INTERVENTIONS

Attention - Focusing the listener's attention on the speaker
1. Give direct instruction (Example: "Listen to what l'm going to say").

2. Shorten input.

3. Use visual aid.

4. Reduce extraneous stimuli.

5. Increase proximity of speaker to listener.
Language

Memory - The speaker's facilitating listener recall
1. Simplify vocabulary.

2. Restate message.

3. Simplify syntax.
1. Use high frequency words.

2. Disseminate group information in easily associated categories.

3. Use groupings categorized by semantic membership (what they are) rather than where or when.

4. Control message length.

5. Control linguistic (or surface) structure.

6. Control restatements - should be exact or will confuse.

7. Control serial position of information - information given last is remembered best, information given in the middle is forgotten most easily.

8. Use careful phrasing - can group words or elements for listener.

9. Increase relevance of material to listener - increases recall 
Other variables that can be controlled to facilitate recall are: linguistic structure, length, and serial position. Wiig and Semel (1980) stated that interchanging words with similar meaning (as in restating a message) go unnoticed when they occur within 25 to 30 seconds. Changes are noticed (and can thus confuse), however, if the delay between repetitions of similar statements is longer than 30 seconds. Conversely, restatements that change the meaning of the sentence are recognized if the delay between repetitions is no more than 45 seconds. Therefore, restating a message must be done carefully because, if done poorly, it can confuse the listener and impair recall.

Simplifying sentence structure is another modification that can improve listener recall. At times, simplification of sentence structure entails shortening the sentence or decreasing the number of clauses or transformations. But not all long statements are difficult to remember. Related clauses can be chunked together and more easily remembered than an equal number of critical, unrelated words contained in one short sentence.

The position of critical words or ideas in a sentence can facilitate recall. Final words are easier to remember than initial words, and ideas or words in middle positions are most difficult to recall. These effects are called primacy (initial word) recall in contrast to frequency (last word) recall. Many learning disabled and developmentally delayed youngsters remember the last words or ideas presented and forget those given first (Bauer, 1977; Hallahan \& Kneedler, 1979). The sequence of ideas or elements in the message can be controlled so that essential information is presented last.

Finally, intonational features and relevance of the message can influence recall. Phrasing, which chunks groups of words together, can facilitate listener recall. Also, relevance of the words or message to the listener can affect desire and ability to remember. The speaker must be aware of what is important or relevant to the listener and formulate messages with that in mind. This can be done by asking the listener about interests, hobbies, and preferences, and then incorporating that information in framing the message.

\section{Comprehension}

When planning interventions that modify the speaker's role, all these elements that facilitate adequate listener performance must be considered. Then, message types accommodating the different levels of comprehension skills must be formed and the child's competence at each level noted.

\section{Modifying Listening Behavior}

Whenever possible, controlling input can ease the burden of children who have difficulty listening well, and it can facilitate their learning the lesson or message. To control all input (considering the variables listed), however, is a formidable, if not impossible, task for even the most conscientious of teachers. Also, one must question whether this would be in the youngster's best interests. Since so much time is spent listening to a wide variety of messages in differing contexts for varied purposes, students should learn strategies that enable them to distill meaning from uncontrolled messages.

Interventions, therefore, should be directed at changing listening behavior. Cognitive and task approach strategies seem appropriate for a number of reasons. First, these intervention techniques appear to promote generalization of strategies learned to other similar situations (Cosgrove \& Patterson, 1978; Douglas, Parry, Marton, \& Garson, 1976; Keogh \& Barkett, 1979). Uncontrolled messages require situation-specific task performance by the listener. Strategy training that generalizes across classes of problems, therefore, appears to be a logical instructional tactic. Second, the focus of these techniques is on creating change in the child's cognitions (the way he or she thinks). Considering how complex and variable listening tasks are, training cognitive skills rather than changing situation-specific behaviors seems more practical.

Cognitive strategies have been defined by Meichenbaum (1980) as strategies that focus on the learner's self-control, self-awareness, and conscious participation in organizing learning. Cognitive strategies typically require students to act as their own trainers or teachers. Verbalization of the instructional sequence or strategy. by the learner is typically included. The teacher models the tactic, and then the child practices it and is encouraged to delay responding, to evaluate different alternative approaches. For example, the child might verbalize, "It's time to listen. What's my plan? Am I following my plan?" Cognitive strategies are more general in nature than are task approach strategies. Task approach strategies (or attack strategies) are more specific to a particular problem and require learning a small set of rote subskills or rules to apply to a specific class of problems (e.g., learning specific strategies that aid memorization) (Lloyd, 1980).

The combination of both intervention techniques seems appropriate to teaching general listening strategies. Maker (1981), in reviewing some of the literature on listening and the learning disabled, found many researchers to be in agreement: Students deficient in 
listening skills can perform as well as normal children after training consisting of verbal rehearsal, strategies of associative clustering, general organizational strategies, or mnemonics. Specific intervention tactics that focus on changing the listener's approach without controlling the input are listed here (and in Table 3) for each level of the listening sequence.

\section{Attention}

A number of recent studies exploring attentional deficits of the learning disabled found that modeling, self-instruction, and reinforcement, in combination, increased attention in the learner (Camp, Blom, Herbert, \& vanDoorninck, 1977; Douglas et al., 1976; Meichenbaum \& Goodman, 1971). As an example of such an instructional strategy, the teacher might first provide a verbal model: "Okay, I'm getting ready to listen. I have to remember to listen for important points. . ." After listening to a message, the teacher then models: "Now what was said?" (restates the message) "What are the important points? What am I supposed to do next?" The child practices the self-instructional techniques and then does the task. Feedback on completion of the task, along with reinforcement, completes the instructional sequence. Finally, the child fades out verbalized selfinstruction and then uses internalized speech to direct task performance.

Abikoff (1979) evaluated 13 studies that used cognitive training to decrease impulsivity and hyperactivity and increase attending, and found the success of such strategies equivocal. The major difficulty appeared to lie not with the strategy itself but in the assumption that all impulsive or attentional behaviors belong to one response class (e.g., assuming impulsive task approach is similar to impulsive, inappropriate class behavior). No evidence suggests that such is the case. Therefore, although cognitive strategies are effective in improving attention when measured within the context of one response class (listening as contrasted with classroom play or written assignments), careful assessment of task requirements should take place before instruction. If the task requirements are similar, generalization or transfer of attentional skills for listening should occur.

\section{Language Competence}

If a student appears to be having difficulty in completing listening tasks because of deficiencies in language development, instruction in specific areas of language development is most appropriate. Interventions aimed at increasing vocabulary, knowledge of word meanings, and syntax might all be necessary. Language instruction, however, is not the focus of this article. Readers interested in specific language strategies should consult Wiig and Semel (1980) or any of the excellent language development programs commonly in use.

\section{Memory}

General memory and organizational strategies given here are a compilation from a number of sources (Alley \& Deshler, 1979; Barker, 1971; Lundsteen, 1971; Maker, 1981). Instruction in such strategies is aimed at facilitating recall of messages containing any type or amount of information. Again, the intervention is planned to change listening behavior.

\section{Strategies Used During the Task}

Rehearsal has been shown to be an effective strategy in increasing recall. The listener should repeat and review what was said during the listening situation. The difference between thought speed and speech speed makes this possible. People can process information twice as fast as they can speak. Rehearsal strategies encourage active participation by the listener - a noted deficiency in many learning disabled youngsters.

Clustering or chunking information is another memory strategy. The student is taught to group ideas under an identifying characteristic. This strategy is facilitated by verbal rehearsal.

Coding is another mnemonic device. Here, the student needs to remember the first letter of each word in a series. The letters cue the appropriate response. Arranging such cues in a more easily recalled sequence (e.g., forming a word with the letters) is a variation of this tactic.

Students also can be encouraged to visualize the information contained in the message. The effectiveness of this technique depends on the type of information given. Concrete information is more easily visualized in an appropriate environment.

Asking questions of the speaker appears to activate participation in listening and recall besides clarifying unfamiliar vocabulary or concepts (Cosgrove \& Patterson, 1978; Patterson \& Massad, 1980). Many learning disabled children, however, have difficulty monitoring their comprehension, and thus may be unable to formulate information-enhancing questions. 


\section{Table 3}

Strategies to Modify Listening Behavior

Attention

1. Peer modeling.

2. Teacher modeling.

3. Verbal rehearsal.

4. Reinforcement.

5. Physical guidance.

Language

1. Increase in vocabulary.

2. Increase in knowledge of multiple word meanings.

3. Increase in syntactic skills.

\section{Memory}

1. Rehearsal during listening.

2. Clustering or chunking information.

3. Coding information (POP for people, organizations, populations; etc.).

4. Visualization.

5. Question asking.

6. Identifying organizational cues (First ..., second ..., etc.)

7. Rehearsal after listening.

8. Summarizing message after listening.

9. Comparing information received to develop categories.

1. Practice at all levels of literal, critical, and appreciative comprehension.

2. Practice in identifying nonverbal messages. 
Sonnenschein and Whitehurst (1980) found that children improved their communication (speaking and monitoring comprehension) by watching poor communication between peers, but they did not improve when watching an adult engaged in poor message giving. A possible instructional strategy derived from this study is to have children model a communication situation with a speaker and listener and then have other children analyze good as contrasted with poor question asking. As a result, listeners might learn to modify the message and message giver to meet their comprehension needs.

Another memory strategy is to look for organizational cues. The student learns phrases that speakers use to organize and emphasize important information. Phrases like, "the next three steps," "the main point I want to make," "first, second . . . finally," and so on should be used to focus attention. Comparing information is another organizational tool. The listener is to note similarities and differences, and then categorize the information accordingly. Identifying main ideas and supporting details and separating them from irrelevant information is another skill that organizes input and aids recall. Taking notes is an extension of this skill and can aid memorization for older students.

\section{Strategies Used After Listening}

Some memory strategies can be applied after the listening task. Students can verbally review what they heard. They might be asked to identify the organizational strategies they are using to remember the information. Reviewing notes is a similar strategy to increase retention of material. Requiring the student to summarize the message can also enable synthesizing or active participation with the input and can enhance comprehension.

\section{Comprehension}

Comprehension and memory strategies are interconnected. The content of the message provides a vehicle for practicing the aforementioned strategies. Learning to apply general or specific listening strategies at one level of comprehension does not inevitably generalize to a different level of comprehension, but research does indicate that general or specific attack strategies enhance generalization across classes (Keogh \& Glover, 1980; Lloyd, Saltzman \& Kauffman, 1980). Therefore, learners must have practice in each area of comprehension. For example, messages in literal, critical, and appreciative listening must be provided, along with training in how to interpret nonverbal messages, to measure listening proficiency. Video tapes or modeling of nonverbal message giving could be used to elicit evaluation of possible meanings.

Cognitive strategies appear to be viable aids in the measurement of listener success. By requiring verbalization before and after listening, the teacher can evaluate the student's level of success with specific or general comprehension strategies. Depending upon evaluation of the verbal, written, or motoric responses required of the listener, the teacher can plan more practice, a different intervention, or conclude current instruction depending upon the degree of behavior change exhibited.

\section{MATERIALS REVIEW}

Many commercial materials are available to aid the teacher in listening instruction. The complexity of listening skills, however, means that no one material meets the needs of all exceptional students. Variables such as language level, attention span, reading level, response format of the material, and always an assessment of the specific listening skills in which each student needs instruction must be considered before matching materials to instructional plans. A short review of a few commercial materials available is included here, to illustrate the range of skills addressed in various programs.

Listening to the World, by R. Goldman \& M. E. Lynch. Circle Pines, MN: America Guidance Service, 1980.

This program has been designed to teach five listening skills: (1) auditory discrimination (environmental as well as speech sounds), (2) selective auditory attention (listening for important sounds and ignoring distracting sounds), (3) auditory vigilance (listening for particular words or sounds), (4) hypothesis testing (identifying words obscured or absent from sentences and then filling in by context clues), and (5) auditory memory skills (including visualization, rehearsal, grouping, and linking). The program provides for practice at varying levels of difficulty as well as lessons that combine the various skills.

The materials are intended for children in kindergarten and early primary grades, and the content reflects the interests of that age level. The 90 lessons can be presented in a variety of ways, including oral presentation by the teacher, tapes and records, songs to be played on the piano, and use of rhythm instruments. Lessons run 15 to 25 minutes each, and the children respond 
orally, motorically, or by using a gameboard. Reading is not required by the student.

This program is adaptable to use with exceptional students and includes suggested behavioral objectives for individualized education plans. Extra activities are not provided for students requiring more practice, though there are suggested activities to be done at home with the family. Teacher participation and instruction is intrinsic to the program, the student could not use this material independently.

Auditory Perception Training II: Listening Skills, by R. Willette, B. Galofaro, \& I. Peckins. Niles, IL: Developmental Learning Materials, 1980.

This new program is modeled after and is a continuation of the well-known DLM Auditory Perception Training Program. It has been developed for middle school or junior high students with identified listening skills deficits. It has been designed to train listening skills in the areas of: figure ground (attending to instructions while ignoring background noise), memory (including practice in remembering sequence and fact recall), imagery (forming a visual image from verbal information), and motor responding (following verbal directions with various motoric responses). The content reflects interests and activities common to middle and junior high students.

Reading proficiency at approximately third grade level is needed to complete lessons in the memory component. Proficiency in simple addition, subtraction, writing of three place numbers, and knowledge of money concepts, as well as reading, are required to complete some lessons in the figure ground component. Little or no reading is required in the motor and imagery sections of the program.

Lessons are 10 to 15 minutes in duration, and students respond on worksheets while listening to the tapes. This program's format allows for the students' independent use. The 20 lessons are divided into two levels for each component. A short list of activities is suggested, in the teacher manual for each component, for students requiring more practice.

Auditory Perceptual Enhancement Program, Volumes 1-4. Tulsa, OK: Modern Education Corporation, 1978.

Four separate components make up this listening skills program. Volume I consists of nine tapes, two lessons per tape, called "Auditory Memory Chunking Techniques." This component contains lessons in the memory organizational skills of chunking by association and categorization. Volume II contains 11 lessons in discrimination of words in isolation and in sentences. Volume III's 18 lessons provide instruction in following directions. Volume IV is titled "Improving Listening Skills: Critical Listening and Speed Listening." This component's objectives are to increase alertness, evaluation of orally presented information, and retention of factual information.

The program is designated by the publishers as appropriate for elementary students through gifted and junior/ senior high school students. This suggests a substantial range in material difficulty within each program, with little practice at any desired level. Previewing the tapes may be a more appropriate way to assess difficulty of materials. Lesson length varies from 7 to 20 minutes. The student listens to a taped lesson and responds on a worksheet or paper. This format allows for individual pacing and independent use of the material.

Scholastic Listening Skills. Unit I: Easy Ears. Unit II: Ear-power (H. Benham, Ed.). New York: NY: Scholastic Book Services, 1977.

Many educators consider listening comprehension and reading comprehension as complimentary skills, and this program combines listening skills with reading. Unit I consists of 40 lessons that cover: following directions, sequence, main idea, predicting outcome, understanding character, drawing conclusions, discrimination of selected sounds, and rhyming. Targeted age ranges are first through third grades, and the worksheets require reading at the first to second grade level. Unit II also contains listening comprehension instruction and specifically addresses listening for significant details, sequencing, finding proof, main ideas, identifying supporting details, predicting outcomes, inferences, drawing conclusions, discriminating between fact and opinion, problem solving, and finding word meaning through context.

This unit is intended for upper elementary age children, and worksheets require reading at approximately the third to fourth grade reading level, though some sheets demand more reading than others. Youngsters can work independently at their own pace because of the tape format, which includes instruction, though independent student usage is not recommended by its authors.

These programs are only examples of the variety of materials available to teachers. The range of listening skills covered by the different programs is evident, and the need for teacher discretion in material selection is 
essential. Assessment of students' entry levels and instructional needs in relation to the listening skills sequence is necessary for appropriate instruction to take place.

\section{IMPLICATIONS}

Evidence that instruction in listening should be incorporated in comprehensive curricula for exceptional children cannot be refuted. Demands often are placed on these children to listen more in lieu of inefficient or dysfunctional reading and writing skills. Therefore, it seems somewhat shortsighted that the issues in developing systematic instructional procedures have been skirted by many special educators. We believe that by developing an operational definition to frame an intervention sequence and then systematically applying those interventions, measurable improvement in listening behavior can occur. Cognitive and task attack strategies seem a logical approach to intervention. Teaching youngsters strategies that generalize across response classes is practical and efficient considering the variability of messages.

Research substantiates these assumptions, but the need for considerably more research centering on the listening behavior of exceptional children is evident. Research should be directed toward identification of listener characteristics in exceptional children and verification of intervention effectiveness. Until a broader research base is developed, the paradigm for listening instruction developed here is a viable and reasonable approach to instruction.

\section{REFERENCES}

Abikoff, H. Cognitive training interventions in children: Review of a new approach. Journal of Learning Disabilities, 1979, 12, 129-135.

Alley, G., \& Deshler, D. Teaching the learning disabled adolescent: Strategies and methods. Denver: Love Publishing Co., 1979.

Asher, S. R. Children's ability to appraise their own and another person's communication performance. Developmental Psychology, 1976, 12, 24-32.

Auditory Perceptual Enhancement Problems, Vols. 1-4. Tulsa, OK: Modern Education Corp., 1978.

Barbara, D. The art of listening. Springfield, IL: Charles C Thomas, 1957.

Barker, L. L. Listening behavior. Englewood Cliffs, NJ: Prentice-Hall, 1971.

Bauer, R. H. Memory processes in children with learning disabilities: Evidence for deficient rehearsal. Journal of Experimental Child Psychology, 1977, 24, 415-430.

Benham, H. (Ed.). Scholastic listening skills. New York, NY: Scholastic book Services, 1977.
Camp. B.W., Blom, G.E., Herbert, F., \& vanDoorninck, W.J. Think aloud: A program for developing self-control in young aggressive boys. Journal of Abnormal Child Psychology, 1977, 5, 157-169.

Cosgrove, J. M., \& Patterson, C. J. Generalization of training for children's listener skills. Child Development, 1978, 49, 513-516.

Devine, T. G. Listening: What do we know after 50 years of research and theorizing? Journal of Reading, Jan. 1978, pp. 296-304.

Dolch, E. W. A basic sight vocabulary. Elementary School Journal, $1936,36,456-460$.

Douglas, V. I., Parry, P., Marton, P., \& Garson, C. Assessment of a cognitive training program for hyperactive children. Journal of Abnormal Child Psychology, 1976, 4, 389-410.

Flavell, J. H. What is memory development the development of? Human Development, 1971, 14, 272-278.

Goldman, R., \& Lynch, M.E. Listening to the world. Circle Pines, MN: American Guidance Service, 1980.

Gordon, T. Parent effectiveness training. New York: Peter H. Wyden, 1970.

Hagen, J. W. Some thoughts on how children learn to remember. Human Development, 1967, 14, 262-271.

Hallahan, D. P., \& Kauffman, J. M. Research on the education of distractible and hyperactive children. In W. M. Cruickshank \& D. P. Hallahan (Eds.), Perceptual and learning disabilities in children: Research and theory (Vol. 2). Syracuse, NY: Syracuse University Press, 1975.

Hallahan, D. P., \& Kneedler, R. D. Strategy deficits in the information processing of learning disabled youngsters (Technical Report \#6). Charlottesville, VA: University of Virginia Learning Disabilities Research Institute, 1979.

Humphreys, M. S., Hall, J. W., \& Wilson, K. P. Incomplete encoding and susceptibility to interference among children with school achievement problems (US HEW OE 300770493). Chicago: University of Illinois Institute for Learning Disabilities, 1980. (Research paper)

Ironsmith, M., \& Whitehurst, G. J. The development of listener abilities in communication: How children deal with ambiguous information. Child Development, 1978, 49, 348-352.

Kazdin, A. E. The effect of vicarious reinforcement on attentive behavior in the classroom. Journal of Applied Behavior Analysis, 1973, 6, 71-78.

Keeny, T. J., Cannizzo, S. R., \& Flavell, H. H. Spontaneous and induced verbal rehearsal in a recall task. Child Development, 1967, 38, 953-966.

Keogh, B. K., \& Barkett, C. J. An ed ucational analysis of hyperactive children's achievement problems. In C. Whalen \& B. Henker (Eds.), Hyperactive children: The social ecology of identification and treatment. New York: Academic Press, 1979.

Keogh, B. K., \& Glover, A. T. The generality and durability of cognitive training effects. Exceptional Education Quarterly, 1980, $1,75-82$.

Kotsonis, M., \& Patterson, C. J. Comprehension monitoring in learning disabled youngsters (Technical Report \#19). Charlottesville, VA: University of Virginia Learning Disabilities Research Institute, 1980.

Lloyd, J. Academic instruction and cognitive techniques: The need for attack strategy training. Exceptional Education Quarterly, 1980, 1, 53-63.

Lloyd, J., Saltzman, N. J., \& Kauffman, J. M. Predictable generalization in academic learning by preskills and strategy training (Technical Report \#23). Charlottesville, VA: University of Virginia Learning Disabilities Research Institute, 1980. (BEH/OE 300770495)

Lundsteen, S. W. Listening: Its impact on reading and the other language arts. Urbana, IL: National Council of Teachers of English, Educational Resources Information Center, Clearing House on the Teaching of English, 1971.

Mager, R. F., \& Beach, K. M., Jr., Developing vocational instruction. Belmont, CA: Lear Siegler, Inc./ Fearon Publishers, 1967.

Maker, C. J., Problem solving. In D. D. Smith, Teaching the learning disabled. Englewood Cliffs, NJ: Prentice-Hall, 1981. 
Markman, E. Realizing that you don't understand: A preliminary investigation. Child Development, 1977, 48, 953-956.

Meichenbaum, D. Cognitive behavior modification with exceptional children: A promise yet unfilled. Exceptional Education Quarterly, $1980,1,83-88$.

Meichenbaum, D., \& Goodman, J. Training impulsive children to talk to themselves: A means of developing self-control. Journal of Abnormal Psychology, 1971, 77, 115-126.

Patterson, C. J., \& Massad, C. M. Facilitating referential communication among children: The listener as teacher. Journal of Experimental Child Psychology, 1980, 29, 357-370.

Rankin, P. T. Listening ability: Its importance, measurement and development. Chicago Schools Journal, 1930, 12, 177-179.

Shelton, M. N. Body language in the classroom. New Mexico School Review, 1974, 50(4), 24-25.

Smith, D. D. Teaching the learning disabled. Englewood Cliffs, NJ: Prentice-Hall, 1981.

Sonnenschein, S., \& Whitehurst, G. J. The development of communication: When a bad model makes a good teacher. Journal of Experimental Child Psychology, 1980, 3, 371-390.

Tarver, S. G., \& Hallahan, D. P. Attention deficits in children with learning disabilities: A review. Journal of Learning Disabilities, $1974,7,560-569$.

Thorndike, E. L., \& Lorge, T. The teacher's workbook of 30,000 words. New York: Teacher's College, Columbia University, 1944.

Torgesen, J. K. The role of nonspecific factors in the task performance of learning disabled children: A theoretical assessment. Journal of Learning Disabilities, 1977, 10, 27-34.

Wiig, E. H., \& Semel, E. M. Language assessment and intervention for the learning disabled. Columbus, OH: Charles E. Merrill, 1980.

Willette, R., Galofaro, B., \& Peckins, I. Auditory perception training II: Listening skills. Niles, IL: Developmental Learning Materials, 1980.

Wilt, M. A. Study of teacher awareness of listening as a factor in elementary education. Unpublished doctoral dissertation, Pennsylvania State University, 1949.

\section{CLASSROOM FORUM}

\author{
By Beverly Dexter \\ Lynchburg College
}

A few weeks ago I heard several of the primary teachers talking about a workshop they had attended on "child-centered" mathematics. Would this approach be useful in special education? How can I switch over from workbooks to this type of approach?

Mathematics is central to the lives of adults and children alike, though we are rarely consciously aware of its influence in our daily routines. Mathematics gives us a way of ordering our experiences; and concepts such as distance, balance, shape, and relationship aid us in understanding and controlling our environment. Childcentered mathematics take into consideration the life experiences of each child and how he or she learns best.

Research has shown us that children under the age of 11 or 12 :

- learn primarily from sensory or physical experiences.

-have difficulty dealing with symbolic thought.

- usually are able to consider only one major dimension of a problem or object at a time.

-learn better from informal procedures than from following rigid methods.

-gain understanding in direct relation to their developmental stage.

-usually cannot successfully deal with abstractions.

-learn to think logically, for the most part, through the use of concrete materials.

The work of Piaget has greatly influenced both regular and special education teachers in their approaches to teaching math. His research revealed that young children learn best from real-life experiences as opposed to abstract assignments or contrived situations. Without a foundation of real-life experiences using concrete or manipulative materials, later symbolic thought and understanding becomes difficult.

Traditionally, mathematics for special education students has consisted of simple computations from textbooks or worksheets that rarely relate to a child's physical experiences within his or her environment. Not only is this approach inconsistent with the way these students learn, but it is also inadequate with regard to basic understanding of mathematics. Thus, mathematics should be a natural result of real-life experiences and real-life needs for the child.

When students are told that math is important to them but are given problems unrelated to their lives, they usually have difficulty mastering the concepts or understanding math's importance. Activities and assignments that have little or no physical relationship to students' real lives are abstract to them since they can deal successfully only with physical or sensory experiences. This is why many adults fear math and avoid teaching it - they were taught math as an abstract subject before they were ready to deal with abstract thought and concepts.

On the other hand, if students are given mathematical experiences related to their everyday lives, they learn that these concepts and skills can aid them in managing their lives, that these are necessary for making choices in the real world. 
To move from the formal or textbook approach to a more student-centered activity approach, the teacher has to find ways to make the transition. One way is through the use of task cards. These cards contain written assignments, or tasks, for the students to perform.

Well-designed task cards have two basic characteristics: (1) they direct students to do something, and (2) they offer a way for the students to communicate what has been accomplished. This communication takes the form of things the children make, their writing, their speaking, or their drawing. Usually some combination of these is best with special education students.

Task cards should be written in the form of openended questions or problems that challenge students to think, yet are not ambiguous. A card for young children might read, "Find how many small shells will be needed to balance the big sea shell on the scale." Children might be asked to make guesses first. Then they could be asked to comment on their results. To bring out deeper understandings with older students, the teacher might pose questions such as: "What did you notice?" "What did you discover?" "Can you see a pattern?" "Do you see a relationship?"
Using task cards, however, can have its dangers and drawbacks. If the teacher prepares them at the beginning of the year and has the children work systematically through them, the cards might become as stereotyped as textbooks or workbooks.

The use of task cards usually evolves through three stages if they are to lead to a more complete childcentered approach:

Initially, ideas come from resource books, math guides, other teachers' cards, and so on. From this stage, teachers start making cards directed to the specific interests and needs of individual students. The third stage is to increasingly limit their use as more and more math work evolves from the real life of the child both inside and outside the school setting. (Role playing shopping trips is a good example.)

Task cards, along with commercial, collected, teachermade, and child-made materials, represent one of the best ways to move from the exclusive or almost exclusive use of textbooks, worksheets, and workbooks to the ultimate goal of utilizing the child and the environment as the source for understanding mathematics. 